\title{
Do Sterilization Processes Really Make Difference in Dialysis-Induced Genotoxicity?
}

\author{
Emna El Golli-Bennour ${ }^{\mathrm{a}, \mathrm{c}}$, Chiraz Zaied ${ }^{\mathrm{a}}$, Chayma Bouaziz ${ }^{\mathrm{a}}$, Yosra Guedri ${ }^{\mathrm{a}}$, , \\ Abdellatif Achour ${ }^{a}, \mathrm{~b}$, Salwa Abid ${ }^{\mathrm{a}}$, Hassen Bacha ${ }^{\mathrm{a}}$
}

\begin{abstract}
The major problem associated with hemodialysis (HD) therapy is the choice of dialyzer membrane matters as well as the mode of sterilization required before utilization. In this context, we aimed to determine the effect of two sterilization processes (steam and gamma rays) on genotoxicity of polysulfone dialysis membranes. A 38-year-old man with end-stage renal disease and one age-matched healthy subject were enrolled in our study. We analyzed lipid peroxidation measured by serum malondialdehyde (MDA) formation and DNA fragmentation assessed by agarose gel electrophoresis and diphenylamine quantification. Our results clearly showed that there is a rising generation of MDA and DNA fragmentation in patient sera during HD session when compared to healthy subject data. This increase in MDA and DNA fragmentation amounts followed respectively the sterilization process. As classified from the more biocompatible one, the steam sterilized polysulfone dialyzer is the top ranked, followed by the gamma rays sterilized one. We concluded that using steam instead of gamma rays for sterilization may improve the biocompatibility of polysulfone dialyzer membranes.
\end{abstract}

Keywords: Dialyzer membranes; Sterilization process; Oxidative stress; Genotoxicity

\section{Introduction}

Hemodialysis (HD) is the routine treatment for chronic renal failure $[1,2]$. The major problem associated with this therapy is the bioincompatibility of dialyzer membranes [3]. Several polymeric membranes have been used as materials for HD and these require sterilization processes before utilization. The methods currently used for sterilization of dialyzers include treatment with ethylene oxide and gamma irradiation.

Manuscript accepted for publication December 14, 2016

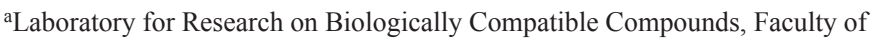
Dentistry, Monastir, Tunisia

${ }^{b}$ Nephrology Department, CHU, Sousse, Tunisia

${ }^{\mathrm{c} C}$ Corresponding Author: Emna El Golli-Bennour, Laboratory for Research on Biologically Compatible Compounds, Faculty of Dentistry, Monastir, Tunisia Email: emnagol@yahoo.fr

doi: https://doi.org/10.14740/wjnu296e
Meanwhile, alternative sterilization modes such as steam sterilization have been suggested $[4,5]$. In this study, we tried to check if the sterilization process really makes any difference in dialysis-induced genotoxicity.

\section{Case Report}

\section{Subjects}

This study involved one HD patient (man, aged 38 years) with end-stage renal disease, who had undergone chronic HD treatment for $4 \mathrm{~h}$, three times a week for 6 years. The patient has given his informed consent. For this study, before sample collecting, the patient underwent dialysis with every membrane type for at least 3 months. Results were then compared with those from one age-matched healthy subject from the general population.

\section{Samples}

Blood venous samples $(5 \mathrm{~mL})$ were drawn from HD patient at the beginning (T0), the middle; after $2 \mathrm{~h}$ (T2) and the end; after $4 \mathrm{~h}$ (T4) of HD session and were placed in heparinized tubes. Serum was obtained by centrifugation at $1,500 \times \mathrm{g}$ for 10 min at $4{ }^{\circ} \mathrm{C}$.

\section{Dialyzer membranes}

Dialyzer membranes include: 1) F6-HPS: polysulfone dialyzer, surface area $1.3 \mathrm{~m}^{2}$ sterilized by steam (M1) and from Fresenius Medical Care AG, Bad Homburg, Germany. 2) APS 650: polysulfone dialyzer, surface area $1.3 \mathrm{~m}^{2}$ sterilized by gamma rays (M2) and from Asahi Kasei Medical, Tokyo, Japan.

All dialyzers are high-flux dialyzers.

\section{Methods}

\section{Lipid peroxidation measurement}

Lipid peroxidation was carried out by the measurement of malondialdehyde (MDA) according to the method of Ohkawa 


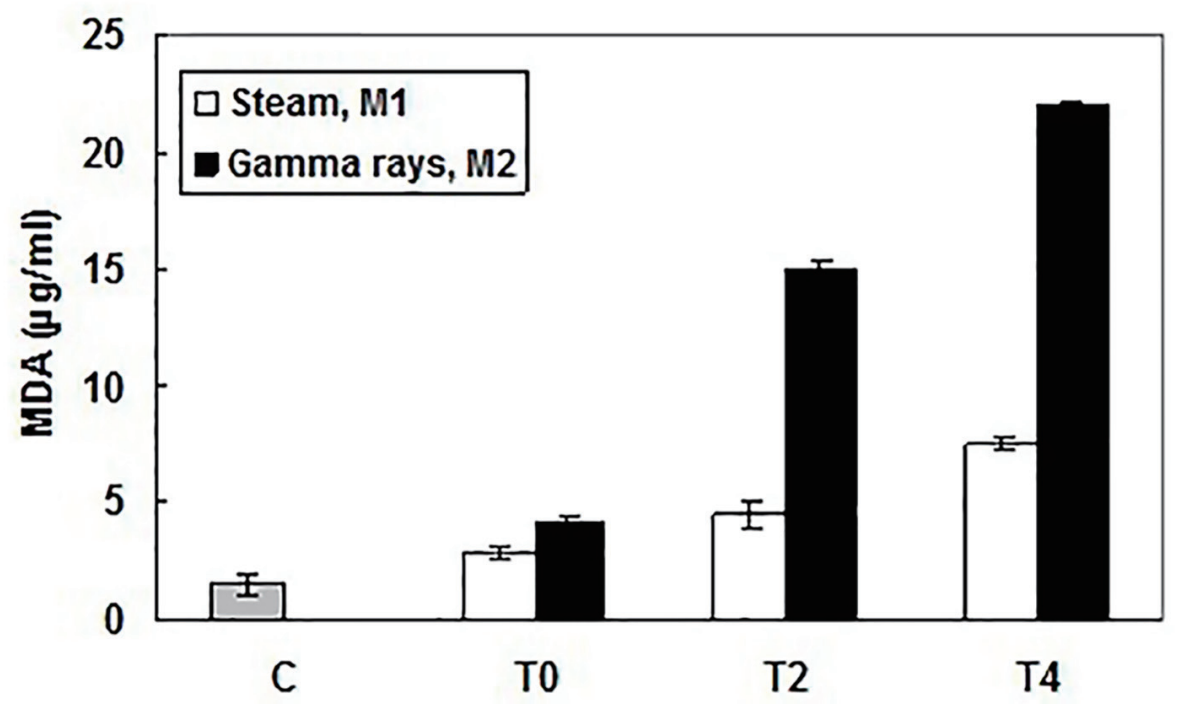

Figure 1. Lipid peroxidation levels in patient and healthy subject sera measured by production of malondialdehyde (MDA), at the beginning (TO), the middle (after $2 \mathrm{~h}, \mathrm{~T} 2$ ) and the end (after $4 \mathrm{~h}, \mathrm{~T} 4$ ) of HD session and using different dialyzer sterilization processes: M1 (sterilized by steam) and M2 (sterilized by gamma rays). MDA amounts $(\mu \mathrm{g} / \mathrm{mL}$ ) were determined according to a standard curve. Results were expressed as mean \pm SD from three independent experiments.

et al (1979) [6]. Serum $(100 \mu \mathrm{L})$ was combined with $0.2 \mathrm{~mL}$ of $8.1 \% \mathrm{SDS}, 1.5 \mathrm{~mL}$ of $20 \%$ acetic acid adjusted to 3.5 of $\mathrm{pH}$ and $1.5 \mathrm{~mL}$ of $0.8 \%$ thiobarbituric acid. The mixture was brought to a final volume of $4 \mathrm{~mL}$ with distilled water and heated at $95{ }^{\circ} \mathrm{C}$ for $2 \mathrm{~h}$. After being cooled at room temperature, $5 \mathrm{~mL}$ of $\mathrm{n}$-butanol and pyridine mixture $(15: 1, \mathrm{v} / \mathrm{v})$ was added to each sample and the whole was shaken vigorously. After centrifugation at 15,000 rpm for $10 \mathrm{~min}$, the supernatant fraction was isolated and the absorbance was measured at 532 $\mathrm{nm}$. The concentration of MDA was determined according to a standard curve.

\section{DNA extraction and quantification}

DNA was extracted from peripheral blood leucocytes using blood DNA purification kit (Promega) and was quantified by UV spectrophotometry at $260 \mathrm{~nm}$.

\section{DNA fragmentation by agarose gel electrophoresis}

Loading buffer $(0.25 \%$ bromophenol blue and $40 \%$ saccharose) was added to $5 \mu \mathrm{g}$ of DNA for each sample. Samples were then analyzed by electrophoresis on a $1 \%$ agarose gel $(1 \mathrm{~h}$ at $80 \mathrm{~V} / 30 \mathrm{~mA}$ ) with a Tris-Borate-EDTA running buffer (44 mM Tris-HCl, $44 \mathrm{mM}$ boric acid, $50 \mathrm{mM}$ EDTA, $\mathrm{pH}$ 8.0), stained with ethidium bromide and photographed with a SynGene GeneStore system.

\section{DNA quantification by diphenylamine}

DNA fragmentation was measured according to the method described by Sandau et al (1997) [7]. Diphenylamine solution $(320 \mu \mathrm{L})$ (in $10 \mathrm{~mL}$ glacial acetic acid: $150 \mathrm{mg}$ diphenylamine, $150 \mathrm{~mL} \mathrm{H}_{2} \mathrm{SO}_{4}$ and $50 \mathrm{~mL}$ acetaldehyde $16 \mathrm{mg} / \mathrm{mL}$ ) was added to each sample tube containing $5 \mu \mathrm{g}$ of DNA, followed by incubation overnight at room temperature. The optical density was determined at $600 \mathrm{~nm}$. DNA fragmentation was calculated as follows: \% fragmented DNA $=(\mathrm{OD}$ supernatant $/ \mathrm{OD}$ supernatant + OD pellet) $\times 100$.

\section{Discussion}

In the uremic state, many factors could be involved in DNA damage, in particular an enhanced generation of oxidative stress $[8,9]$. The increased DNA damage in cells of patients with chronic renal insufficiency and long-term HD therapy may be causally linked to the high cancer incidence, in particular, cancer of the kidney, prostate, liver, and uterus, compared with the general population $[10,11]$. In the present study, we have demonstrated that the sterilization processes of dialyzer membranes can interfere with the oxidative and genotoxic status of HD patient. As compared to healthy subject, there was a rising generation of MDA in patient blood during HD session. Nevertheless, this MDA production differs with the sterilization process. Indeed, at the end of HD session (T4), the serum MDA amounts were about 5 and 15 folds respectively for steam sterilized M1 and gamma rays sterilized M2 as compared to the MDA amount in control (Fig. 1). Consequently, utilization of radiation as sterilization process induced more ROS than the steam procedure. Even so, the steam method for sterilization is still the most biocompatible one. In fact, we have previously shown that steam-sterilized membranes improve endothelial cell viability and limit lipid peroxidation enhancement when compared to ethylene oxide or gamma rays- 


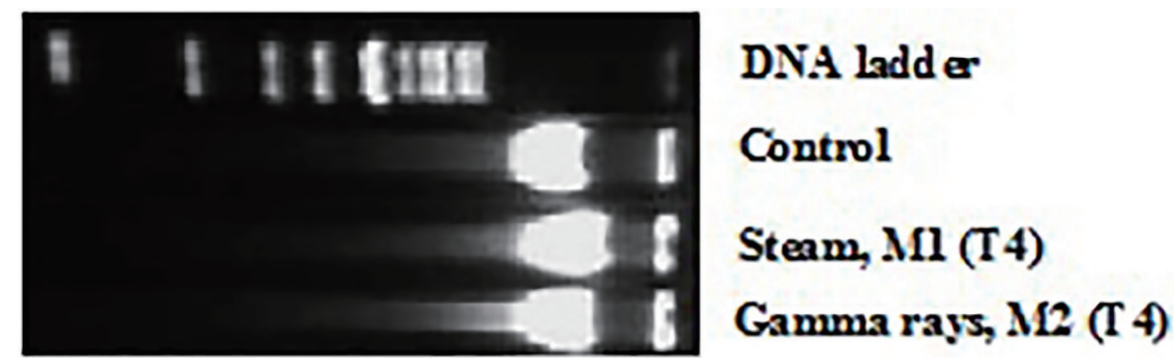

Figure 2. DNA fragmentation induced by exposure to different dialyzer membranes sterilization mode: M1 (sterilized by steam) and M2 (sterilized by gamma rays), in patient leucocytes at the end (after $4 \mathrm{~h}, \mathrm{~T} 4$ ) of HD session and revealed by agarose gel electrophoresis.

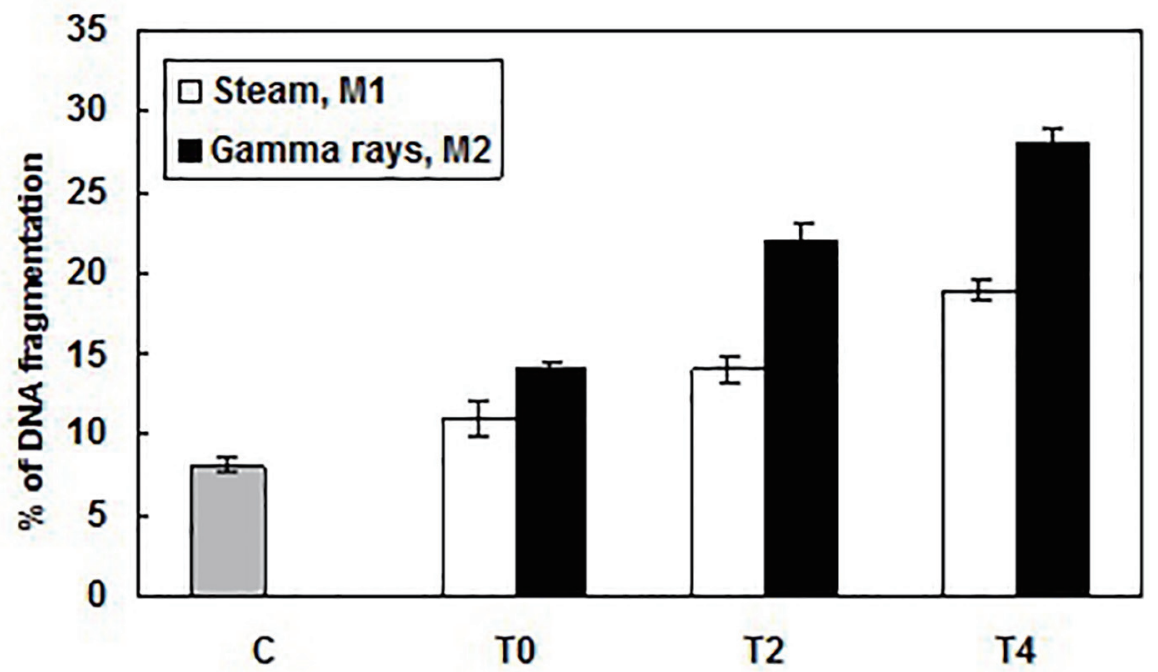

Figure 3. Percentage of DNA fragmentation caused by exposure to different dialyzer membranes sterilization mode: M1 (sterilized by steam) and M2 (sterilized by gamma rays), in patient leucocytes at the beginning (T0), the middle (after $2 \mathrm{~h}, \mathrm{~T} 2$ ) and the end (after $4 \mathrm{~h}, \mathrm{~T} 4$ ) of HD session and determined using the diphenylamine assay. Results were expressed as mean \pm SD from three independent experiments.

sterilized ones [12].

Slight DNA fragmentation was observed with dialyzer sterilized by steam (M1). The DNA fragmentation profile was more pronounced with dialyzer sterilized by gamma rays (M2). DNA fragments (DNA ladders) showing varying sizes between 750 and 2,000 base pairs were clearly visible after agarose gel electrophoresis, but no specific DNA fragments were detected when controls were analyzed (Fig. 2). Using a quantitative analysis of DNA fragmentation, a significant effect was observed after peripheral blood leucocytes exposure to different sterilized dialyzer membranes. This DNA fragmented level reached at the end of HD session $19 \pm 0.624 \%$ and $28 \pm 0.975 \%$, respectively for steam sterilized M1 and gamma rays-sterilized M2 (Fig. 3). However, these genotoxic effects should be consequences of oxidative injury. Our finding is in concordance with other data that report a significant DNA fragmentation level in HD patient lymphocytes [13, 14].

Finally, steam sterilization of dialyzers offers considerable safety advantages to the patient and is preferred to other sterili- zation modes, such as gamma irradiation.

\section{Acknowledgments}

This research was supported by Le Ministere Tunisien de l'Enseignement Superieur, de la Recherche Scientifique et de la Technologie, through the Laboratoire de Recherche sur les Substances Biologiquement Compatible.

\section{References}

1. Iseki K, Tozawa M, Takishita S. Determinants of prescribed dialysis dose and survival in a cohort of chronic hemodialysis patients. Clin Exp Nephrol. 2003;7(3):231237.

2. Chan R, Brooks R, Erlich J, Chow J, Suranyi M. The effects of kidney-disease-related loss on long-term dialysis patients' depression and quality of life: positive affect as a 
mediator. Clin J Am Soc Nephrol. 2009;4(1):160-167.

3. Hoenich NA. Membranes for dialysis: can we do without them? Int J Artif Organs. 2007;30(11):964-970.

4. Muller TF, Seitz M, Eckle I, Lange H, Kolb G. Biocompatibility differences with respect to the dialyzer sterilization method. Nephron. 1998;78(2):139-142.

5. Aucella F, Tetta C, Tessore V, De Nitti C, Vigilante M, Gatta G, Grandone E, et al. Is steam sterilization really making any difference in dialysis-induced cytokine release? Int J Artif Organs. 2002;25(9):832-837.

6. Ohkawa H, Ohishi N, Yagi K. Assay for lipid peroxides in animal tissues by thiobarbituric acid reaction. Anal Biochem. 1979;95(2):351-358.

7. Sandau K, Pfeilschifter J, Brune B. Nitric oxide and superoxide induced p53 and Bax accumulation during mesangial cell apoptosis. Kidney Int. 1997;52(2):378-386.

8. Inagi R, Miyata T. Oxidative protein damage with carbohydrates and lipids in uremia: 'Carbonyl stress'. Blood Purif. 1999;17(2-3):95-98.

9. Himmelfarb J, Stenvinkel P, Ikizler TA, Hakim RM. The elephant in uremia: oxidant stress as a unifying concept of cardiovascular disease in uremia. Kidney Int.
2002;62(5):1524-1538.

10. Matas AJ, Simmons RL, Kjellstrand CM, Buselmeier TJ, Najarian JS. Increased incidence of malignancy during chronic renal failure. Lancet. 1975;1(7912):883-886.

11. Iseki K, Osawa A, Fukiyama K. Evidence for increased cancer deaths in chronic dialysis patients. Am J Kidney Dis. 1993;22(2):308-313.

12. Golli-Bennour EE, Kouidhi B, Dey M, Younes R, Bouaziz $\mathrm{C}$, Zaied C, Bacha $\mathrm{H}$, et al. Cytotoxic effects exerted by polyarylsulfone dialyser membranes depend on different sterilization processes. Int Urol Nephrol. 2011;43(2):483490.

13. Horoz M, Bolukbas C, Bolukbas FF, Kocyigit A, Aslan M, Koylu AO, Gumus M, et al. Assessment of peripheral DNA damage by alkaline comet assay in maintenance hemodialysis subjects with hepatitis $\mathrm{C}$ infection. Mutat Res. 2006;596(1-2):137-142.

14. Bagatini PB, Palazzo RP, Rodrigues MT, Costa CH, Maluf SW. Induction and removal of DNA damage in blood leukocytes of patients with type 2 diabetes mellitus undergoing hemodialysis. Mutat Res. 2008;657(2):111115. 